\title{
A SOCIOLINGUISTIC PERSPECTIVE OF CODESWITCHING IN FRENCH AS A FOREIGN LANGUAGE CLASS IN MALTA AND ITS IMPLICATIONS FOR LEARNING ${ }^{1}$
}

\begin{abstract}
Codeswitching (CS) between Maltese L1, English L2 and French as the target language (TL) in the French as a Foreign language (FFL) classroom in bilingual Malta is known to be a widespread reality, despite many French teachers' claims that ideally lessons should be delivered in French only (Bezzina 2016). The aim of this study is to evaluate, on the basis of corpus analysis, whether a wise use of previously known languages in the Foreign Language (FL) classroom can support the learning of the FL. Recordings of sixteen FFL lessons delivered at two different learning levels by two teachers in Maltese secondary schools give indications as to the quantitative extent of the use of the L1, L2 and French L3 in these contexts. A qualitative analysis is carried out of the functions fulfilled in the teachers' discourse by each of the three languages involved in the Maltese FFL context. The corpus analysis takes into account the structural manifestation of language juxtaposition. Interviews with the two teachers involved in the sampling exercise provide participants' feedback on the analysis results. These results endorse literature attesting that L1 use in FL classrooms allows better content management and transmission, and helps establish a generally positive classroom ambiance. An interpretation is attempted of the social meaning of the observed switching in the context of the societal factors that mark language use in bilingual Malta, and the relationship between the macro- and micro-sociolinguistic dimensions of CS in the FL classroom is investigated.
\end{abstract}

Keywords: language alternation teacher talk

$\begin{array}{ll}\text { functions } & \text { structure } \\ \text { dominant language } & \text { social meaning }\end{array}$

\section{Introduction}

This chapter focuses on the effects of codeswitching, or the to and fro movement between more than one language as a person draws on different resources present in his / her linguistic repertoire in order to make meaning of the world while communicating (Garcia 2011).The term codeswitching (CS) is adopted in this study as an umbrella term encompassing all instances of alternation between different languages (namely Maltese, English and French) within the same spoken interaction, whether these instances are intra-sentential or inter-sentential (within or beyond the boundaries of the same utterance), and irrespectively of whether they are limited to single lexical items or cover much broader stretches of speech.

\footnotetext{
${ }^{1} \mathrm{We}$ are indebted to Professor Antoinette Camilleri Grima of the University of Malta for her advisory role in the completion of the main empirical study contained in this work, and for her insightful comments at the inception stage of this chapter.
} 
One situation that alerted us to the need of looking at this phenomenon more closely is that students reading for a university course in preparation to become teachers of French as a Foreign Language (FFL) in Malta have expressed the difficulty they encounter when they have to decide whether they should elect French as the medium of instruction and expression in their classes, or whether they should allow the use of Maltese and English, as their learners' previously known languages, during their French lessons (Gauci 2016). It is true that mixed messages are transmitted to the student teachers by different examiners who assess them during the school-based teaching practice periods that they have to carry out in part fulfilment of their teacher training course. Some examiners expect to observe exclusive French-language communication in the lessons they assess, the rest demanding that student teachers codeswitch in such a way that their teaching can reach and be effective with learners of diverse ability. Maltese teachers of FFL responding to a questionnaire also manifest divergent perceptions on the subject (Bezzina 2016), some believing that the L1 should be avoided in order to maximise exposure to the target language (TL), and others upholding the view that alternating the TL and the L1 offers benefits in the FFL classroom on the practical, relational, attitudinal and academic levels.

The teachers' contrasting attitudes and the student teachers' perplexity stem from the existence of two distinct schools of thought on the subject of language distribution as medium of instruction in the teaching and learning of foreign languages. Moore (1996) affirms that studies related to the influence of the L1 on L2 learning generally led to the consideration that in order to avoid the parasitic appearance of L1 traits in learners' L2 performance, the L1 needed to be totally barred from L2 classes. For some, resorting to the L1 in the foreign language (FL) class is taboo, and they view mixed language productions extremely negatively, as an indication of a lack of spoken competence (Thompson and Harrison, 2014). However, already in 1996, Moore attests an evolution towards more flexibility on the subject, and since, much research has been conducted with results showing that a wise use of the L1 can prove useful in several ways in the flow of FL classroom interaction and in the imparting, reception and understanding of FL content (Causa 1996, 1998, Greggio \& Gil 2007, Ahmad 2009, Lee \& Macaro 2013, Camilleri Grima \& Caruana 2016). Specifically for French as TL, a number of studies have also shown how resorting to the L1 can boost learning and communication and improve classroom control and relationships (Moore 1996, 2002, Castellotti 2001, Ehrhart 2002, Molander 2004, Maarfia 2008, Yiboe 2010, Soku 2014).

In the light of the lack of consensus on the usefulness of CS in the FFL teaching and learning context in Malta, the present study aims to provide indications based on data, as to the benefits, or otherwise, of L1 presence in Maltese FFL classes. The study is carried out by means of a quantitative exercise flanked by a qualitative analysis of a corpus built upon transcriptions of sixteen forty-minute lessons delivered by two teachers in two different Maltese secondary schools (Gauci 2016), which will be referred to henceforth as the Gauci corpus. Before proceeding to a theoretical review of some literature on the question of language use in FL teaching in Malta, and to the empirical study focusing on French, a brief description will be provided of the context of the teaching of FFL in Malta.

\section{French as a school subject against the backdrop of bilingual Malta}

The National Curriculum Framework (NCF) issued by the Ministry of Education and Employment in 2012, states that all Maltese formal school learners are entitled to learning at least one FL. This normally happens as from the age of 11, when learners move on into 
secondary school. Prior to starting this five-year secondary cycle, they are asked to choose one FL to study. The Maltese island's proximity to Italy, having led to historical and cultural ties with the Italian language, is the reason which explains why Italian is by far the most popular language (Caruana 2012). French is traditionally the second most widely chosen FL, though for various reasons, it is fast losing ground to other languages, especially Spanish and German (Bezzina 2016).

In Malta, Maltese is the national language, and an official language along with English. Bilingualism characterises the Maltese educational context, with the majority of learners speaking Maltese as a first language and having learnt English as from the start of primary school, and sometimes earlier than that, through prior exposure to the language in the family setting. English is the first language of a minority of Maltese individuals. Most children belonging to this demographic category go to private, fee-paying schools (around 10\% of children) where the dominant language of instruction and communication is English. Verbal interaction in Maltese and CS dominate in State school contexts (slightly more than $50 \%$ of children). The two schools involved in this study belong to the educational category which is referred to as "Church schools" in Malta (Catholic schools catering for around $40 \%$ of Maltese children, heavily subsidised by State funding), where most, but not all, learners speak Maltese as L1. Due to this linguistic situation, in the presentation of the empirical study, L1 will refer to Maltese, L2 to English, and L3 to French as TL. The mixed use of Maltese and English in education has been the subject of a number of studies, some of which we shall briefly review, although we will be focusing on studies related to FL teaching in Malta. CS behaviour in the FL classroom therefore already has bilingualism as a generalized backdrop in the Maltese context and the mixed use of different languages may at first glance appear to be simply a natural extension into the classroom of CS habits which are more or less shared by all Maltese speakers in their daily interaction in "Maltese" (Busuttil Bezzina 2013, Caruana and Camilleri Grima 2014): even while thinking they are speaking in the national language, Maltese individuals spontaneously codeswitch with English to a greater or lesser degree.

For many persons, this linguistic behaviour is natural, as speakers instinctively draw on elements deriving from the languages in their repertoire, even as they keep Maltese as their basic code. The following example, taken from the Busuttil Bezzina (2013) corpus, targeting stylistic variation in Malta, illustrates this spontaneous and uninhibited language alternation. In the example, a former Deputy Prime Minister (L1) is informally taking stock of his 'to do' list with his close assistant as they discuss the imminent visit of a foreign dignitary while they round off a day's work:

\begin{tabular}{l|l} 
1) L1: pero' da= ifhimni / jien 1- & L1: but about this listen here / what is \\
importanti huwa / illi naghtuh is-security & important for me is that / we provide him \\
li hemm bżonn / minghajr ma jkollna & with the necessary security / without having \\
fortress mentality = gifieri li Madonna & $\begin{array}{l}\text { a fortress mentality which means that for } \\
\text { heaven's sake they're going to kill him here }\end{array}$ \\
Santammen se joqtluhulna &
\end{tabular}

In many cases, however, CS can be rather voluntary, as speakers resort to the language of prestige in order to show off their level of education and / or their real or aspired high(er) social status; in the latter case CS may appear to be tinged with affectation. Thus in the Busuttil Bezzina corpus (2013), an assistant pharmacist (L2) recorded as speaking mostly Maltese in informal conversation with family members, is also recorded as linguistically trying to keep up appearances through CS when discussing business with an English-dominant speaker (L1) who 
co-owns an important financial agency. At one point when she realizes she has uttered a phrase in Maltese, she quickly repeats it in English (my mother tieћu nofs / my mother takes half):

2) L1) [...] da= kien / three five nine four il-holding kien / so if it was split up between how much four?

L2: four / and my mother

L1: $\quad$ and my mother / ehe [...] five / ii- imma l-mother użufruttwarja?

L2: my mother tiehu nofs / my mother takes half

L1: in-nofs

L2: $\mathrm{u}$ ahna the other half we divide in four ASSISTANT PHARMACIST: FINANCIAL AGENT
3) L1: [...] this one was / three five nine four the holding was / so if it was split up between how much four?

L2: four / and my mother

L1: and my mother / right [...] five / bu- bu- but the motheris she a usufructuary?

L2: my mothertakes half / my mother takes half

L1: the half

L2: and us the other half we divide in four

Although Maltese enjoys an institutionally strong position, being the language of Parliament, the Law Courts, the Church, and the privileged language of the public sector, English is the privileged language in the educational system. It is the language of the University and is the intended medium of instruction and evaluation of most subjects like Mathematics, the Sciences, Geography, Accounting, Economics, etc. The larger, more important private companies' records, annual general meetings, and most internal written communication are held in English. The English-speaking minority of the population is mostly made up of members or aspiring members of the elite, for reasons of upbringing but also due to a wish to demarcate oneself from the rest of the 'common' section of the population (Busuttil Bezzina 2013).

Attitudes towards language use are divergent across factions of the Maltese population. A section of the English-speaking population looks down upon the larger Maltese-dominant community. Inversely, speakers with stronger feelings of loyalty and patriotism towards Maltese as the national language view the English-speaking minority as a snobbish, disloyal group. In popular culture, a pervasive judgment persists of CS as a highly stigmatised form of speech, and of codeswitching individuals as incompetent speakers in any language. Thus Diacono's prescriptive Gheltijiet u Barbarizmi fil-Malti (1977) describes the "invasion" of Maltese by Anglicisms as a "national shame", a "threat" and an "illness" and stresses the need to "purify journalistic and popular Maltese vocabulary" (my translation). Questioned about their views on the common practice of alternating Maltese and English in the same sentence in a questionnaire (Busuttil Bezzina 2013), around 40\% of the Maltese adult respondent sample qualify such speakers as snobbish, $17.5 \%$ as impudent, $10 \%$ as ignorant, $16.3 \%$ as ridiculous and $5.6 \%$ as lacking knowledge of how to speak well.

The question thus arises of the extent to which this sociolinguistic dimension of CS can be found to mark the FL classroom, if at all. What happens when spoken communication becomes taxed with the added complication of a third language? What functions does CS serve in the Maltese FFL classroom? How far can these micro-level functions of CS be interpreted as integrated within, or even reflecting, macro-level societal patterns? In other words, do code choices in the FL classroom stem from larger, stable, societal perceptions of the values associated with specific languages used in the Maltese community? This discussion will thus try to 'capture [the] link between macro- and micro-level factors in [the] interpretation of CS utterances' (Boztepe 2003, p.13). 


\section{Studies on CS in Maltese FL lessons}

Camilleri Grima has written extensively on the subject of bilingualism in Maltese education and on CS. A number of Camilleri Grima's works (1995, 2001, 2003) illustrate, through the analysis of different corpora collected from Maltese classrooms, how lessons are accomplished bilingually. For those subjects where English is the intended formal medium of instruction, in most Maltese school contexts "there is continual interaction between the written text in English as the basic point of reference, and the oral discussion in Maltese (with codeswitching) [through which] participants reason out problems for themselves, and find their ways to the solutions required" (2013, p. 4). Through a review of some studies (Sollars 1988, Ventura 1991, Farrell and Ventura 1998, Farrugia 2009) focusing on the Maltese bilingual classroom mostly for scientific subjects where the formally intended medium is English, Camilleri Grima (2013) shows that there is a clear orientation in the significance of their results: resorting to Maltese alleviates difficulties of understanding, readability, and written performance, especially in the case of lower achieving students. On the contrary, imposing an English-only policy equates to silencing the students, who refrain from expressing their needs.

More recently, Maltese researchers have tackled the question of the bilingual FL classroom in Malta. Some draw on Gauci's corpus built in 2011 using interaction recorded during Italian lessons. Gauci and Camilleri Grima (2012, p. 2) observe that CS and the use of the L1 serve as "an important 'adjustment' for understanding to be achieved", whilst enabling participants to "accomplish other important social and discourse functions". CS is seen as fulfilling the three functions in the classification proposed by Cazden (1988). It is thus used to teach the language as subject-matter, as when the teacher repeats the explanation in the L1 to clarify a grammatical rule previously explained in Italian or to make the learners fully understand her instructions. It plays a role in managing the flow of social interaction: Maltese is used to elicit or acknowledge a response and to show the teacher's irritation with certain behaviour. Thirdly, the L1 is the language of personal identity, allowing speakers to express their feelings and attitudes. For instance, a teacher reverts to Maltese while he describes traits in his character which explain his reactions to learners' behaviour. The study includes interviews with six teachers of Italian, most of whom mention the benefits of CS in instilling motivation, building rapport, explaining grammar and instructions, and reaching out to weaker learners.

Caruana and Camilleri Grima (2014) observe that language contact in the Italian classroom stimulates participation in discussions, as both teacher and learners constantly alternate between the L1 and the TL, and weaker learners also get involved. Metalinguistic talk in the L1 renders grammatical notions understandable to learners. Classroom management appears to be effective when undertaken in the L1, for instance in dealing with unruly behaviour. The L1 also plays a role in interlinguistic comparisons for a better assimilation of TL vocabulary, as lexically and morphologically many Maltese words are cognates from Italian terms. Camilleri Grima and Caruana (2016) examine, through a conversation analysis at the level of speech acts accomplished in the TL and / or in the L1, how teacher-learner interaction in a whole-class activity leads to approximation to the TL and thus to effective learning. An unfortunate observation is that teachers consistently direct closed questions at their learners, such that the latter group can often only produce one- to three-word answers and does not find space to practise longer stretches in the TL. Patterns are also observed in the relationship between specific speech acts and language distribution: for instance, elicitation and informative acts are more often produced in Italian, though Maltese or a mixture of both languages are also at times used for these communicative purposes. A balance appeared in the use of Italian and Maltese for accomplishing directives, those in Italian being activity-related and those in Maltese aimed 
at class control. CS is seen to help lead to approximations of grammar rules and is the means through which informal talk is conducted.

To our knowledge, no studies have as yet been published on the subject of classroom language use in the area of the teaching of Spanish in Malta, although one such study is in progress (Dalli forthcoming). Aquilina (2012) investigates the languages used in a number of observed lessons of German as a FL in two Maltese Church schools, delivered by a native and a non-native teacher. She reviews literature which views resorting to the L1 in the FL classroom as both a positive and a negative practice, and most learners in her questionnaire disagree with the idea of exclusive German communication in lessons. However, her conclusions show that she concords with the explicit directive in the Handbook for the Teaching of German as a Foreign Language (2011) of the Directorate for Quality and Standards in Education, that the medium of instruction when teaching German should be the TL itself, and that switching to Maltese and English during lessons should be minimal and justified: " $[\mathrm{t}]$ he researcher believes that if $[\ldots]$ teachers reflect more on their language choices, they would resort less to English and Maltese. For many FL students, the classroom is [perhaps] the single environment, where they can listen [to] and practise the language as target" (2012, p. 70). Aquilina observes that German is mostly used in relation to the topic of the lesson while Maltese and English are used by both teachers and learners in most classroom situations and interactions. She finds that there is a reasonable input in German in teacher-learner talk, but German use is minimal in learner-teacher and learner-learner interaction.

More specifically for French, Abela (2011) acknowledges that the classical concept of immersion or exclusive TL use has in many contexts given way to practices based on the maximization of pupils' previous knowledge. Nevertheless, for her empirical research, she proposes, for an eight-lesson session, a convention imbued with TL-only qualities to a selected class, determining which language can be spoken in which lesson type or situation. As for the German scenario, Abela claims that for French "[i]nstitutionally there is still insistence that French should be used [...] so that students will be able to communicate in French" (2011, p. 88). In reality, official texts issued by the Directorate for Quality and Standards in Education and the Curriculum Management and eLearning Department, such as the Handbook for the Teaching of French as a Foreign Language (2012) and the French as a Foreign Language: Teaching Objectives and Learning Outcomes for Forms 1 and 2 (2012) are silent on the matter. One does find, however, in the obsolete syllabus for Forms 3-5, which is the curriculum available for these school years, dating from 2001-2002, a statement that it is imperative that the teacher of French should want and be able to speak fluently in the TL in class (Programmes de français 2001-2002+). Pressure to conform to this seems to still be tacitly present as many teachers feel guilty when resorting to the L1 in the FFL class (Bezzina 2016 and personal communications).

Abela (2011) feels that "there seems to be a certain complacency about the use of languages in classes, so students do not make the effort to move out of their comfort zone" (Ibid.). Students' journals and questionnaire answers in fact reveal that the negotiation of a TL-only method between the researcher and themselves did not work as they did not welcome more talk in the TL. Their teacher's method of free drawing upon the L1 gives them more security. Conclusions from Abela's questionnaire and her focus group for teachers of FFL show that most teachers feel it is important not to exclude the L1 from their lessons as this may further discourage learners from studying French. 
As mentioned above, in Bezzina (2016), results of a questionnaire administered to Maltese FFL teachers, specifically seeking to unravel teachers' perceptions on the use of CS, show that a significant number of them are still influenced by a direct method teaching ideology advocating exclusive TL use for the sake of exposing the learners to it and to avoid laziness. Surprisingly though, the majority of teachers appear to have moved away from this view and express awareness of the benefits that CS may offer. The main justifications they provide for this are a concern for the learners' well-being, as CS is believed to instil motivation and confidence in them, and for the quality of learning, based on the belief that CS helps learners understand better and faster, and participate actively. Other reasons mentioned are that it helps teachers reach out to learners of different ability, allowing the latter to exploit all their linguistic baggage, and that it enhances classroom management and relationships. In Bezzina (2017), observations of two Maltese FFL teachers' verbal practices (as in the Gauci 2016 corpus) are generally in line with what teachers expressed about the usefulness of CS in the above-mentioned questionnaire, as reported in Bezzina (2016). A categorisation of examples of CS excerpts reveals a structural mix of smooth bilingual discourse along with explicit and non-explicit translation (see 3.2). As Camilleri Grima and Caruana (2016) observed for Italian, it is evident for French also that learner talk is hardly encouraged in any language, as teachers' questions tend to be closed. The TL appears to be largely underused in the FFL classroom.

Given these observations in the Maltese FL teaching context, we will now further investigate the medium of instruction issue in the Maltese FFL setting, basing ourselves on a detailed study carried out by Gauci (2016).

\section{The research study}

Gauci (2016) set out to research whether the disputed and sometimes hushed down practice of CS is in reality well present in Maltese classrooms; researchers do state that it is difficult to bar it from FL classrooms (Levine 2011), and this would apply all the more to the case of Malta where CS is, as explained above, a most natural type of linguistic behaviour in everyday conversation. The study also aims to investigate which functions the L1 (Maltese), L2 (English) and L3 (French as TL) are made to fulfil by the teachers and the learners.

For these purposes, in 2015 Gauci recorded a total of 16 lessons, of which half were delivered by a teacher in a girls' Church school, and half by a teacher in a boys' Church school. Maltese Church schools in fact have a separate gender policy at secondary level. Gauci's locations of recordings depended on teachers' acceptance and gender is not exploited as a possible variable in this study. The two teachers and their learners were audio-recorded in Form 1 (A1 beginner level) and Form 3 (A1+ level) classrooms. Two teachers who taught at both Form 1 and Form 3 levels were needed, to allow comparisons between language use at both levels. This was important to maintain result authenticity: Greggio and Gil (2007) have too many variables in their attempt to compare language use at two different levels, using different teachers.

No specific requests were made to the teachers, apart from that they were to conduct their lessons as usual. The researcher tried not to influence the natural course of the lessons; she sat at the back and did not interfere in any way. It was explained to the learners that she was observing and audio-recording the lessons and that any data, including the name of the school and teacher, would remain anonymous. They soon got used to her presence and ignored her. As a precaution however, the first lesson in both schools was not used for the analysis. The researcher kept a journal, to help her while effecting and interpreting the transcriptions of the recordings. An interview with each teacher was held following the recordings, in which they 
could interpret the language distribution patterns observed in their class. Ethical procedures were observed.

The qualitative analysis of the functions of CS was carried out on eight transcribed lessons, and focused on the functions of CS instances. The quantitative analysis related to the amount of teacher talk vis-à-vis learner talk (and in which language these are conducted) was carried out on twelve transcribed lessons, and involved percentage calculations of data in Excel spreadsheets and a number of tables. A combined approach to the study of language alternation was adopted, following what Boztepe calls 'two distinct but related directions', or two 'approaches [...] not in contradiction, but complementary to each other' $(2003$, p.3): the specific functions fulfilled by CS are pointed out at the same time as a description is made of the CS structures, according to the classifications in Causa (1996) and Camilleri Grima (2013).

\subsection{Teacher and learner talk and the weight of codeswitching}

Word-count percentages taking into account averages of twelve lessons (six at Form 1 beginner level, six at Form 3 A1+level) reveal that the two recorded teachers use the L1 (Maltese) more than the TL as language of instruction, at both Form 1 and Form 3 levels. The significant gap between the two languages at Form 1 level (36\% French vs. 56\% Maltese) narrows down at Form 3 level (43\% French, 47\% Maltese). One reason for this could be that teachers feel that learners at their third year of studies of the TL can understand them better, so that it is more fruitful to use French at this level.

Table 1: Number of words pronounced by the teachers at the two different learning levels and percentage calculations

\begin{tabular}{|c|c|c|c|c|}
\hline $\begin{array}{c}\text { Teachers (Form 1, } \\
\text { beginner) }\end{array}$ & French & Maltese & English & $\begin{array}{c}\text { Total number } \\
\text { of words }\end{array}$ \\
\hline Total & $1468(36 \%)$ & $2255(56 \%)$ & $341(8 \%)$ & $4064(83 \%)$ \\
\hline $\begin{array}{c}\text { Teachers (Form 3, } \\
\text { A1+) }\end{array}$ & French & Maltese & English & $\begin{array}{c}\text { Total number } \\
\text { of words }\end{array}$ \\
\hline Total & $2210(43 \%)$ & $2405(47 \%)$ & $524(10 \%)$ & $5139(86 \%)$ \\
\hline
\end{tabular}

At Form 1 beginner level, students emulate their teachers' language distribution habits, with French featuring at 32\% of their speech, and Maltese surpassing it at the 50\% mark. Form 3 learners however overrule this pattern, with the TL accounting for 56\% of their speech, and Maltese lagging behind at 30\%. Form 3 learners' spoken competence therefore seems to have developed as the learners seem to find it easier than beginners to verbally contribute in the TL.

Table 2: Number of words pronounced by the learners at the two different learning levels and percentage calculations

\begin{tabular}{|c|c|c|c|c|}
\hline $\begin{array}{c}\text { Learners (Form 1, } \\
\text { beginner) }\end{array}$ & French & Maltese & English & $\begin{array}{c}\text { Total number } \\
\text { of words }\end{array}$ \\
\hline
\end{tabular}




\begin{tabular}{|c|c|c|c|c|}
\hline Total & $271(32 \%)$ & $423(50 \%)$ & $157(18 \%)$ & $851(17 \%)$ \\
\hline $\begin{array}{c}\text { Learners (Form 3, } \\
\text { A1+) }\end{array}$ & French & Maltese & English & $\begin{array}{c}\text { Total number } \\
\text { of words }\end{array}$ \\
\hline Total & $485(56 \%)$ & $260(30 \%)$ & $119(14 \%)$ & $864(14 \%)$ \\
\hline
\end{tabular}

One also needs to bear in mind that the percentage of TL use also includes instances of brief reading of words and expressions from textbooks, so that if spontaneous discourse in French were to be exclusively considered, the percentages relating to TL use would actually be smaller. Example 3 illustrates how of the 15 words pronounced by the teacher in French in this excerpt, the first nine are read from the textbook:

\begin{tabular}{|c|c|}
\hline $\begin{array}{l}\text { 3) } \mathrm{T} \text { : exercice N / l-istess / devinez le } \\
\text { personnage // x'inhu saut à l'élastique ? / } \\
\text { mhm ? / c'est un type de sport } \\
\text { - FORM 3, GIRLS }\end{array}$ & $\begin{array}{l}\text { exercise } \mathbf{N} \text { / once again / guess who // what } \\
\text { is saut à l'élastique [bungee jumping]? / } \\
\mathrm{mhm} \text { ? / it's a type of sport }\end{array}$ \\
\hline
\end{tabular}

English features at $8 \%$ of language use by teachers at Form 1 and at 10\% at Form 3 levels, and slightly higher in learner talk (18\% in beginners' speech, and 14\% in Form 3 learners' speech). It echoes the fact that this language occupies a privileged position in the educational sector in Malta, since use of the L2 is very often observed to happen when referring to objects and activities typically linked with the school context, such as "diary", "notes", "classwork", "test", "postcard", "positive report" and "lesson's objective". Examples 4-7 illustrate how English terms are inserted into stretches of speech otherwise realized in Maltese:

\begin{tabular}{|l|l|}
\hline 4) T: f'dan il-unit se naghmlu 1-arlog $\dot{g}$ & $\begin{array}{l}\text { in this unit we are going to cover saying the } \\
\text { - FORM 1, GIRLS }\end{array}$ \\
\hline
\end{tabular}

\begin{tabular}{|c|c|}
\hline $\begin{array}{l}\text { 5) T: il-gimgha d-dieћla se nitilfu 1-lesson } \\
\text { allura l-homework ghall-gimgha ta' wara se } \\
\text { jkun - FORM 1, GIRLS }\end{array}$ & $\begin{array}{l}\text { next week we'll be missing the lesson so the } \\
\text { homework will be for the following week }\end{array}$ \\
\hline
\end{tabular}

6) L1: miss jien number three ghamiltha c'est votre prof - FORM 3, GIRLS

miss me number three I did it c'est votre prof [it's your teacher]

The corpus is also dotted with the occurrence of English words, expressions and numbers, which are commonly used as such in Maltese, like "as we go along", "trick", and "happy birthday". Furthermore, another important function played by the L2 is the expression of technical terms in metalinguistic speech, another sign of the association between English and scholarly activity. Examples 7 and 8 illustrate this happening in the teacher's speech, and example 9 shows one occurrence in learner discourse:

\begin{tabular}{|c|c|}
\hline $\begin{array}{l}\text { 7) } \mathrm{T} \text { : ghalhekk nghidilko } \\
\text { article il-kelma halli } \\
\text { masculine jew feminine - } F\end{array}$ & $\begin{array}{l}\text { that } \\
\text { the }\end{array}$ \\
\hline
\end{tabular}

\begin{tabular}{|c|c|}
\hline $\begin{array}{l}\text { 8) T: àpreposition / gieli tfisser at / gieli to / } \\
\text { gieli in - FORM 1, BOYS }\end{array}$ & $\begin{array}{l}\text { à is a preposition/ sometimes it means at / } \\
\text { sometimes to / sometimes in }\end{array}$ \\
\hline
\end{tabular}




\begin{tabular}{|c|c|}
\hline 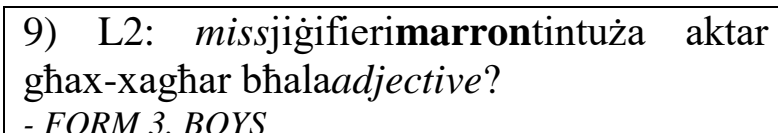 & $\begin{array}{l}\text { miss you mean marron is used more for hair } \\
\text { as an adjective? }\end{array}$ \\
\hline
\end{tabular}

We have so far seen percentages pertaining to the three languages present in Maltese FFL lessons. Although percentages of overall teacher and learner talk do not at first sight strictly have close affinities with the question of CS, it is worth mentioning them briefly as they may provide clues for our discussion, in which we will try and understand why certain patterns emerge in this analysis of results. At this stage it will be sufficient to point out the huge discrepancy between average percentages of teacher and learner talk. Thus, at Form 1 level, teachers hold the floor $83 \%$ of the time, and learners have to make do with the remaining $17 \%$ of class talk. At Form 3 level, even more time (86\%) is occupied by teacher talk, as opposed to the learners' meagre $14 \%$.

\subsection{Main functions served by CS}

A qualitative review of some of the functions which often appear to characterize the use of CS will help to understand why the teacher resorts to the constant movement between languages. For reasons of space, only instances of teacher talk can be retained here, though it must be kept in mind that the teacher's choice of language will at times have been influenced by the learners' prior choice of language in moments of interaction.

For purposes of structural description of the excerpts hereunder, the switching instances retained for illustration of the main uses of $\mathrm{CS}$ will be divided into two main categories: explicit and non-explicit switching (Camilleri Grima 2013). Explicit translation occurs in those instances where an idea is produced in one language and repeated in another, often, but not necessarily, with formal markers attracting attention to the switch. Non-explicit translation involves a reiteration of an idea, with modifications to the content uttered as the speaker passes from one language to another.

Apart from these two categories, we will also take into account a number of subcategories as listed and described in Causa (1996). Causa distinguishes between pure code-switching ("l'alternance codique pure" in Causa's original text), which is the passage from one language to another without any particular intonational or declarative shifts, and bilingual speech ("le parler bilingue") in which exclamations and discourse markers are produced in a language different from that of the main utterance. These often serve to express positive evaluation, or for the opening and closure of a sequence (Idem.). Explicit switching corresponds to repetitions ("les répétitions") which aid memorisation by an association of the TL term or expression with an L1 equivalent. Reformulations ("les reformulations") are contiguous expressions of a notion in which one or several elements are modified. Completions ("les achèvements") normally occur after a pause or hesitation, when the speaker moves on to the other language without having finished his utterance in the first language, and finally, interpolated clauses ("les incises") are strictly metalinguistic comments, or stem from a more natural interactional pattern (Idem.)

Non-explicit switching is often resorted to by the teacher for class control purposes. In the following two examples, an instruction utterance addressed to the whole class (ex. 10) and a content control question addressed to a particular student (ex. 11) in the TL are followed by 
utterances in the L1, constituting instances of pure CS. These utterances are an order to a particular student (ex. 11) and an order disguised by a question (ex. 10), by which the teacher wants to effectively reestablish order in class:

10) $\mathrm{T}$ : trouvez la méthode // page six / lesti hemm wara ? - FORM 3, GIRLS

find your textbook // page six / are you ready at the back?

11) T: Samuel qu'est-ce que tu as entendu? Samuel what have you heard? / come on sit / bilqiegћda sew ejja - FORM 3, BOYS down properly

In example 12 it can be observed that when the teacher is not after correcting behaviour but after making her learners focus on the French content, the switch follows the opposite direction: L1 > TL. The type of switch is structurally still an instance of pure non-explicit CS:

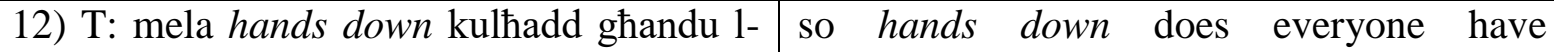
karta tal-bieraћ? / faites attention s'il vous yesterday's sheet? / pay attention please

plaît - FORM 3, BOYS

The last example retained to illustrate CS for class control is structurally different though, the explicit repetition of the order (TL > L2) serving to strengthen the illocutionary force of the teacher's request for quiet:

13) T: alors silence / no more comments please - FORM 3, BOYS

so silence / no more comments please

A second important use of CS is for content (ex. 14) and lesson sequencing (ex. 15) management. It is interesting to note a profusion of discourse markers in these instances, of which two examples are retained here. In example 14, where the completion type switch is of an explicit nature, the first occurrence of the discourse marker "issa" (now) marks a development with some shift in the orientation of the teacher's argumentation, while the second occurrence is a preannouncement of the teacher's development of the point through her example of the preposition and article being used in context.

14) T: issa / meta jkollok il-préposition à u 1-article féminin / la se tigì à la issa bhal per eżempju à la campagne-FORM $1, B O Y S$

now / when you have the preposition à and the feminine article / la becomes à la now like for example à la campagne [in the country]

In example 15, the final part is a reformulation-type switch with very little modification of the original French statement. The French discourse marker "maintenant" is used as a link between the current and previous lesson, stressing that what will follow is a natural development. In the Maltese reformulation the discourse marker "jigifieri" is preferred, with the teacher showing her will to reassure and be understood by her students as she translates the aim of the sequence to them.

15) T: u lbierah / hier / on a discuté les prépositions bil-à hux vera ? / u ghidna li dawn irridu nitghallmuhom bhala expressions as they are / maintenant on va and yesterday / yesterday / we discussed the prepositions with à right? / and we said that we need to learn them as expressions as they are / now we are going to conjugate the two 
A third use of CS is for the evaluation of learners' answers or interventions. Evaluation is at times produced in the TL (ex. 16, first part of ex. 18), at other times in the L1 (exs. 17 and 18), and more rarely in the L2. These examples are mostly instances of non-explicit CS related to Causa's bilingual speech type: the teacher switches languages, producing the central part of the utterance in one language and the word of praise in another. The positive evaluation may be repeated through different words of praise, for more effect, as in ex. 17, whereas the negative evaluation in ex. 16 is toned down:

\begin{tabular}{l|l} 
16) T: à le teżisti hdejn xulxin? & T: does à le[to the] exist near each other? \\
L3: le & L3: no \\
T: bravo / u x'nghidu minflokha? & T: well done / and what do we say instead? \\
FORM l BOYS &
\end{tabular}

17) T: arrête huwa er verb / mela biex ha jispic̈a?

L4: bil-e

T: arrête is an er verb / so with what will it end?

L4: with an $e$

T: bil-e tajjeb / mela la montre arrête /

T: with an $e$ good / so the watch stops / good prosit - FORM 1, GIRLS job

\author{
18) T: très bien / qu'est-ce que ça signifie \\ l'Espagne? \\ T: very well / what does it mean Spain? \\ L5: Spanish \\ L5: spanjol \\ T: not exactly though / espagnol is Spanish \\ $\mathrm{T}$ : mhux eżatt imma / espagnol \\ Spanjol - FORM 1, GIRLS
}

CS also clearly plays a role in teachers' elicitation of learners' responses. It is interesting to note that as in examples 19 and 20, very often the elicitation ends in the learners' L1 or L2, which seems to act as a form of encouragement for the learners to participate ; in fact, in example 19, long pauses are not filled by the learners as no learner is willing to speak until the teacher translates the question into English, thus showing she will equally accept an answer which is not in the TL:

19) T: quelle heure est-il ? // quelle heure est-il ? // qu'est-ce que cette question signifie ? /// what does the question mean? L6: what time is it? - FORM 3, BOYS
T: what time is it ? // what time is it? what does this question mean? /// what does the question mean?

L6: what time is it?
20) T: il est trois heures et demie / $\mathrm{x}$ 'inhi demie? konna ghamilnieha meta ghamilna 1age
$\mathrm{T}$ : it is half past three / what is [demie] half? we had done it when we did the age L7: half 
As was alluded to at the start of this section, answering learners' questions, almost invariably produced in the L1, often triggers teachers' reactions of resorting to the L1 or L2, with some reference to the TL when the focus of the exchange is a particular word or expression. In example 21, the learner's explicit switch is replied to by the teacher's multiple non-explicit switching in an instance of pure metalinguistic CS:

\begin{tabular}{|l|l|}
\hline 21) L8: minflok bruns allura ma tistax & L8: so instead of bruns can't you say \\
tghid marron / brown? & $\begin{array}{c}\text { marron / for brown? } \\
\text { T: marron ukoll teżisti imma bruns } \\
\text { T: marron exists as well but bruns is used } \\
\text { tintuża aktar ghax-xaghar bћala adjective } \\
\text { more as an adjective for hair }\end{array}$ \\
\hline
\end{tabular}

CS is often used to clarify a point in the course of an explanation, as in example 22, which concerns the complementary distribution of the verbs "aller" (to go) and "partir" (to leave). The metalinguistic role of English is once again shown, in the interpolated clause and in the term which is offered as its alternative:

22) T: dak li hu iktar ta' kuljum qishom / nużaw il-verb aller / il-verb partir / it requires more length qishom / jew transport warajhom - FORM 1, BOYS
T: for uses which are more common like / we use the verb to go / the verb to leave / it requires more length like / or a means of transport following them

Related to this use is the role CS plays in the teacher's explanation when the aim is to solve a misunderstanding. In the next example, the repeated use of the Maltese verb "fisser" (to mean) renders the switches clearly explicit, whereas the English words reflect the habit of resorting to English for the scholarly practice of translation and for technical terms:

\begin{tabular}{|c|c|}
\hline $\begin{array}{l}\text { 23) } \mathrm{T} \text { : montrer tfisser to show u montre } \\
\text { huwa noun u jfisser watch / imma ghandek }\end{array}$ & $\begin{array}{l}\mathrm{T} \text { : montrer means to } \\
\text { noun and it means wa } \\
\text { because they resemble }\end{array}$ \\
\hline
\end{tabular}

Also closely related to the clarification function is teachers' use of CS for the purpose of checking learners' comprehension of their explanations or instructions. This function is also reminiscent of that of elicitation, as these examples often end with a question prompting the learners to confirm or show their understanding, as in this instance of non-explicit bilingual speech type switch, where the discourse marker "mela" is produced in Maltese, along with two other words which accompany it, the rest of the explanation having been communicated in the TL:

\begin{tabular}{|c|c|}
\hline $\begin{array}{l}\text { 24) T: ce sont les moyens de transport en } \\
\text { général d'accord ? / mais il manque les } \\
\text { articles / il faut ajouter les articles / x' ha } \\
\text { naghmlu mela? } \\
\text { L9: se jkollna l-verb partir u l-verb aller } \\
\quad \text { - FORM 1, BOYS }\end{array}$ & $\begin{array}{l}\text { T: they are the different means of } \\
\text { transport right? / but the articles are } \\
\text { missing / we need to add the articles / what } \\
\text { are we going to do then? } \\
\text { L9: we're going to have the verb partir and } \\
\text { the verb aller }\end{array}$ \\
\hline
\end{tabular}

For the sake of ensuring comprehension, complex instructions tend to be mostly delivered by the teachers through the use of the L1 and some inclusion of L2 terms: 


\begin{tabular}{|c|c|}
\hline 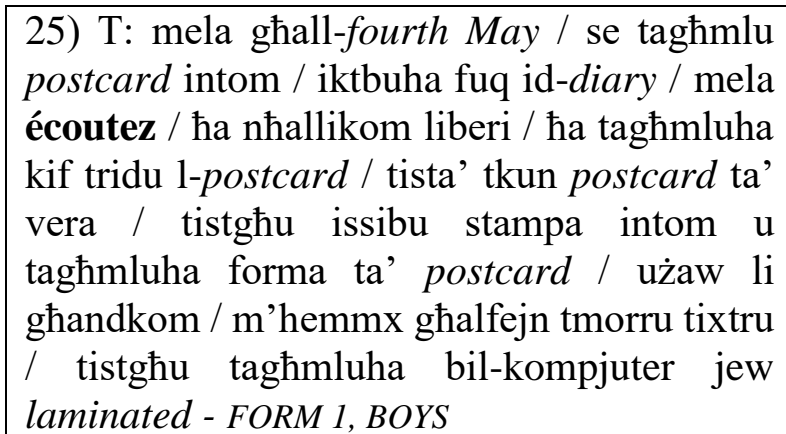 & $\begin{array}{l}\text { T: so for the fourth May / you are going to } \\
\text { make a postcard / write it on the diary / so } \\
\text { listen / I'm leaving you free / you can do the } \\
\text { postcard as you wish / it can be a real } \\
\text { postcard / you can find a picture and make it } \\
\text { into the form of a postcard / use what you } \\
\text { have / there's no need to go and buy one / you } \\
\text { can do it with your computer or laminated }\end{array}$ \\
\hline
\end{tabular}

Time saving is another important function fulfilled by CS, as the next example, also involving instruction-giving, illustrates through an instance of non-explicit pure CS:

\begin{tabular}{|c|c|}
\hline $\begin{array}{l}\text { 26) T: mela / ma tantx ghad fadlilna hin / ha } \\
\text { toqoghdu en groupes de deux jew trois / ha } \\
\text { taqbdu karta } \mathrm{w} \text { tiktbu xi points } \\
\text { - FORM 3, GIRLS }\end{array}$ & $\begin{array}{l}\text { T: so / we don't have much time left / you're } \\
\text { going to stay in groups of two or three / } \\
\text { you're going to grab a paper and write some } \\
\text { points }\end{array}$ \\
\hline
\end{tabular}

Advice is also observed to be delivered in the learners' L1 and L2, the reason being the teachers' wish to build closeness, complicity and collaboration with the learners thanks to the whole group's shared languages:

\begin{tabular}{|l|l|}
\hline 27) T: oqoghdu attenti ghall-question words & $\begin{array}{l}\text { T: pay attention to the question words mind } \\
\text { ta / aghmlu revision - FORM 3, GIRLS }\end{array}$ \\
\hline
\end{tabular}

In this description of the functions related to language distribution patterns in the classrooms of two FFL teachers, examples from learner talk are very limited. The description is thus partial, yet it can be stated that similar structural patterns of movement from one language to another can be observed in the discourse produced by learners. A detailed study of the functions that CS is made to fulfil by learners is warranted though before one can decide to what extent these functions are similar to the teachers'.

At first glance, the impression one gets at the end of this enumeration of micro-instances of CS and of the purposes served in each case, is that it is highly difficult to trace any patterns between the use of particular languages and the carrying out of such and such a function. Our next aim is therefore to discuss whether any patterns can be gleaned from this apparently disorderly spread of the particular languages in the teacher's discourse.

\section{Interpretation of results from the language teaching perspective}

When considering the above CS examples overall, it can be concluded that structurally all types of CS patterns presented in Causa (1996) and Camilleri Grima (2013) are used in the FFL classroom context, although the non-explicit and the pure CS types appear to be more frequent than other forms. The teachers resort to it for instance when handling metalinguistic explanations. When pure CS is used for orders, phrases in Maltese seem to be more frequent when addressing discipline and desired behaviour, while phrases in French crop up more often when the teachers wish to bring the class to focus on content. Discourse markers in French, like écoutez(listen) and alors(so), often appearing in completion and reformulation structures, are not uncommon, yet they are certainly outnumbered by Maltese markers, among which mela 
(so) and = gifieri (so / which means) regularly punctuate the teachers' speech. Evaluation by the teachers of learners' attempts to answer their questions occurs mostly in Maltese, although this doesn't exclude the function being fulfilled in French. It appears that with clarification, timesaving and explaining complex instructions, one can more readily associate longer stretches in Maltese than the use of the TL. One pattern which often emerges in the teachers' spoken production examples above is their initial tackling of a notion in French, followed by elicitation in the L1 or L2 to check learners' understanding or to get their feedback, or else by stretches of explanation provided by the teachers themselves, also in the L1 and / or L2.

From the point of view of the types of activities carried out, it thus transpires that teachers do use the TL to some extent in their explanations, but the L1 and L2 remain dominant in this area. When interviewed, teachers state that they feel the need to use the L1 and L2 for grammar work sequences and metalinguistic discourse. This is in line with previous findings where grammar is considered to be too difficult to tackle in the TL if one wants to ensure comprehension of rules, etc. (Maarfia 2008, Camilleri Grima and Caruana 2016, Bezzina 2017).

During the interviews with the two participating teachers, the latter state that other competences require less use of the $\mathrm{L} 1$, such as listening comprehension, reading and spoken production. In pair or group work or in other forms of learner-learner interaction though, learners communicate in the L1. Focusing on perceptions, Cambra (1997) in fact observes that the use of a FL is often felt to be unnatural when participants speak the same L1. It is somehow embarrassing or strange for speakers sharing the same L1 to adopt the TL as spoken medium.

The result yielded by this study's investigation of whether different CS patterns can be observed at two distinct levels of learning of FFL is that beginners do actually resort more to the L1 and L2 than learners who have progressed further in their studies of the language. Teachers also use the L3 more with the more advanced learners. This reflects the observation in Bremnes (2013) which is based on a Norwegian sixth form context. However L1 and L2 use remains important at the A1+ level for both categories of speakers, and this corroborates findings in international studies stating that it is not only beginners who feel the need for L1 use in the FL classroom (Macaro 2001). When interviewed, the two teachers involved in this study claim that the determining factor influencing language distribution in their lessons is learners' level of competence (i.e. whether it is a gifted or a weaker group), rather than the stage in their learning process, so much so that sometimes they feel they can use the L3 more with a beginner than a more advanced class.

The motivations for using CS, listed by the two interviewed teachers, remain at a rather superficial level, and they fail to mention any of the series of CS functions identified above. This reflects the probability that they are not formally aware of the possible functions of language switching in class, and that they were not trained to reflect about them. They both firmly believe that ideally interaction in FFL lessons should be exclusively carried out in the TL, therefore embracing the more traditional TL-only ideology. Nevertheless, experience has led them to realize that classroom realities call for a more flexible approach. Both teachers invoke mixed ability groups of learners as the main factor which renders CS mandatory. An attempt by one of them to instaur a TL-only environment led her to conclude that such a setting is fit for more gifted learners and demotivates the rest of the class which will be unable to understand what is going on.

The teachers also refer to a certain laziness on the learners' part, thus echoing Abela (2011) whose failed experience in the application of a TL-only experiment led her to conclude that 
students dislike more talk in the TL. In reality, it is difficult to judge either the teaching or the learning side for lack of effort to use the TL more extensively and / or more meaningfully, without having been in a situation where one can observe classroom dynamics over a long period of time. Surely though, the teachers as responsible adults should not forgo their role as leaders in the classroom in order to please the learners and should not abdicate from their need to push the learners a step further whilst not accepting "laziness", if it is really the case that learners are manifesting this attitude. Educators need to work on their relationship with the learners whilst ensuring that their academic role of making students practise the FL is fulfilled well, through relevant and purposeful activities and linguistic behaviour.

\subsection{Interpretation of results from the sociolinguistic perspective}

To return to the macro-level issues raised in 1.1, how is social meaning created and negotiated in this specific context, as a product of the observed interaction? Certainly, the criterion of the frequency of CS recorded in the corpus echoes the pervasiveness of CS in the discourse of most Maltese individuals, as described above. It was attested that the L1 was by far the dominant code in this corpus, at the expense of the L3. The L2 was relatively little used. Let us keep in mind that the population of Church schools is, as we hinted before, constituted of a very homogeneous group: single-sex, Catholic, non-migrant, largely Maltese-speaking learners. Teachers, aware of this configuration, and sensitive to it, thus elect the main language of their public as main medium of instruction in what is probably an effort at making their explanation of content, activities and expectations as widely understood as possible.

At the same time, the limited use of English is a sure sign that the more voluntary type of CS which tends to be used by some Maltese speakers in an effort to impress and to display social standing is absent from this context. English was used, as we saw, for conveying technical, metalinguistic terms, school-related terms and expressions with which any Maltese stretch of speech is commonly interspersed. The adoption of Maltese may thus reflect, on the teachers' part, a will to achieve convergence, to accomodate towards the speech of their students (Giles \& Powesland 1975; Giles \& Smith 1979), in an effort to show solidarity with them. The relegation of the TL to a secondary place in their spoken production may be a sign that this relationship is verging on complicity, a possible reflection of teachers' acknowledgment of the subject matter's difficulty and of their willingness to bridge the knowledge gap as a result of this recognition. Teachers may be reacting to the need to approach their learners as members of the 'same' group, for their own well-being and especially for the sake of their subject. As members of the academic staff and moreover as bearers of a FL to which Maltese learners have no exposure outside the classroom, these teachers may subconsciously feel that they run a double risk of themselves (and consequently their subject) being rejected as foreign or as 'outsiders' to the in-group.

\section{Conclusion}

The greatest cause for concern identified through these classroom observations is the imbalance between the amount of teacher and learner talk. This discrepancy shows that a very different interactional and organisational arrangement marks the two observed FFL classrooms than for instance what Stoltz (2011) observed in the Swedish FFL context, where learner talk accounted for $64.3 \%$ of the total number of words produced. It is not perhaps unrealistic to believe that such situations reflect the reality of FL classrooms, and not only those, in Malta. The dominance 
of teacher-talk was also observed in the Italian as a FL context in Camilleri Grima and Caruana (2016).

What seems to be causing this is teachers' directing of closed questions to the learners, of the "what" or "who" or "when" type, for instance. Thus learners' scope for speech is limited to one-word or a couple of words replies. Teachers should be more adventurous and challenge their learners with open questions of the "why" and "how" type, and plan activities encouraging learner interaction.

Teachers are of course pressured by syllabus demands and examination setup and have themselves been exposed to a traditional method of learning. The problem is that their own method of teaching, as Bremnes (2013) concludes for the Norwegian context, focuses on grammar, text comprehension and on sentence analysis, translation and construction. No spontaneous communication by the learners occurs in the TL, which is mostly used to show examples. Learners know rules but are unable to form longer stretches of speech. Other research conducted on the Maltese context corroborates the situation of the teacher as dominant figure (Camilleri Grima 1995, Muscat and Farrugia 2012), and learners' extreme discomfort and difficulty to express themselves in French are the main observations in Bondin (2014), whose aim was to study spoken interaction between FFL learners.

The study is of course limited by the very small number of teachers recorded in their lessons, which calls for caution against any generalisation of observations made. It would also be interesting to extend the study of the functions fulfilled by CS from the learners' perspective, and to obtain learners' views on language use in the FFL classroom.

Further recordings of other teachers' lessons, perhaps in different school contexts, would be helpful. For instance, it would be interesting to question and verify whether different configurations of language use would emerge in FFL classrooms in the private, Englishspeaking schools. It is very likely that functions fulfilled by and values associated with the different languages would reveal themselves as radically distinct from what was observed in the homogeneous Maltese-dominant context of the Catholic schools. And it is also legitimate to wonder what is happening as regards language use and attitudes in the State schools, where the substantial influx of non-Maltese speaking migrant children is mostly being absorbed.

Overall, the study of the functions realized through the movement between languages leads us to conclude that CS is a useful tool in a mixed ability setting, and protects learners from demotivation and confusion. Teachers' language switching helps learners understand better, as the majority of Maltese FFL teachers themselves maintain from experience (Bezzina 2016). It helps learners contribute verbally in class, to some extent. It is a time-saving strategy enhancing clarity and aiding content and classroom management. Teachers seem to lack formal training in the language distribution issue and wish they could benefit from this (Idem.), and this certainly needs to be tackled in their preparation and in continuing professional development.

The CS pattern observed is certainly far removed from the number of studies in which teachers show very negative attitudes towards CS, which often is the case when the learners' L1 is not the dominant language of the country or the school, as in Ramirez \& Milk (1986). The strong position of Maltese as official and national language explains the difference from such contexts. The teachers' reaching out to their learners through CS between their native language and the TL shows very clearly that in the Maltese FFL classrooms observed, CS is not at all the subject of negative attitudes and is not seen as a deviation from a norm, but as a helpful strategy for 
bilinguals to exploit their language repertoire in a more effective way. The observed realities call for a more in-depth study of a perhaps measurable effect that the use of CS may be having on learners' academic achievement and of the ways in which it may be contributing to forging their attitude to language varieties present in the Maltese context.

\begin{tabular}{|c|}
\hline TRANSCRIPTION CONVENTIONS \\
\hline $\begin{array}{l}\text { Italics : speech produced in English } \\
\text { bold }: \text { speech produced in French } \\
\text { Normal : speech produced in Maltese } \\
/, / /, / / / \text { : pause - brief, medium, long } \\
\\
\text { : overlapping speech }\end{array}$ \\
\hline $\begin{array}{ll}\text { bu- } & \text { : interrupted words } \\
\mathrm{da}= & : \text { suppression of a phoneme or syllable, normally a feature of informality } \\
? & \text { : interrogative intonation }\end{array}$ \\
\hline
\end{tabular}

\section{References}

ABELA, C. (2011) Perceptions of the Use of Different Languages in the Teaching of French in Malta. Unpublished dissertation (B. Ed. (Hons.), University of Malta.

AHMAD, B. H. (2009) Teachers' Code-Switching in Classroom Instructions for Low English Proficient Learners. English Language Teaching, 2, p. 49-55.

AQUILINA, T. (2012) Language use during the Teaching and Learning of German as a Foreign Language in Malta. Unpublished dissertation (B. Ed. (Hons.), University of Malta.

BEZZINA, A.M. (2016) Teachers' Understanding of the Use of Language as Medium of Instruction in French as a Foreign Language Lessons. Malta Review of Educational Research, 10(2), p. 277-296.

BEZZINA, A.M. (2017) Translanguaging Practices in the Teaching of French as a Foreign Language in Malta. Malta Review of Educational Research, 11(1), p. 75-95.

BONDIN, S. (2014) La réalisation de l'interaction verbale en français par des collégiens et des lycéens maltais. Unpublished dissertation (B. Ed. (Hons.), University of Malta.

BOZTEPE, E. (2003) Issues in Code-Switching: Competing Theories and Models. Teachers College, Columbia University Working Papers in TESOL and Applied Linguistics, 3(2), p. 127.

BREMNES, M. (2013) L'usage de l'alternance codique dans les cours de français en Norvège. Analyse de son utilisation dans trois cours de première année au lycée. Unpublished dissertation (Master), University of Bergen.

BUSUTTIL BEZZINA, A.M. (2013) La variation stylistique en maltais. Etude des usages concrets de la langue appuyée sur une approche contrastive des phénomènes variationnels en maltais et en français. Unpublished thesis (PhD), Université Paris Nanterre / University of Malta.

CAMBRA, M. (1997) Gestion des langues en classe de langue étrangère. Le poids des représentations de l'enseignant. ELA 108, p. 423-432.

CAMILLERI, A. (1995) Bilingualism in Education. The Maltese Experience. Heidelberg: Julius Groos Verlag. 
CAMILLERI GRIMA, A. (2001) Language Values and Identities: Codeswitching in Secondary Classrooms in Malta. In: HELLER, M. and MARTIN-JONES, M. (eds.) Voices of authority. Education and linguistic difference. London: Ablex Publishing, p. 213-234.

CAMILLERI GRIMA, A. (2003) 'Do as I say not as I do.' Legitimate Language in Bilingual Malta. In: HUSS, L., CAMILLERI GRIMA, A. and KING K.A. (eds.) Transcending monolingualism. Linguistic revitalisation in education. Lisse: Swets \& Zeitlinger, p. 53-65.

CAMILLERI GRIMA, A. (2013) A Select Review of Bilingualism in Education in Malta. International Journal of Bilingual Education and Bilingualism. Available from:

DOI:10.1080/13670050.2012.716813.

CAMILLERI GRIMA, A., and CARUANA, S. (2016) Interaction and approximation to the target language during Italian lessons in Malta. Malta Review of Educational Research, 10 (2), p.253-275.

CARUANA, S. (2012) Italian in Malta: A socio-educational perspective. International Journal of Bilingual Education and Bilingualism, DOI: 10.1080/13670050.2012.716816.

CARUANA, S. and CAMILLERI GRIMA, A. (2014) L'italiano a Malta e la commutazione di codice in contesti didattici. Paper presented at the conference of the SLI, Udine, September 2014.

CASTEllotTi, V. La langue maternelle en classe de langue étrangère. Paris: Clé International.

CAUSA, M. (1996) L'alternance codique dans le discours de l'enseignant : entre transmission de connaissances et interaction. Les Carnets du Cediscor, 4, p. 111-129.

CAUSA, M. (1998) Maintien, transformation et disparition de l'alternance codique dans le discours de l'enseignant, du niveau débutant au niveau avancé. Etudes de linguistique appliquée, 108, p. 457-465.

CAZDEN, C. (1988) Classroom discourse. Portsmouth: Heinemann.

DALLI, C. (forthcoming) Translanguaging in the Spanish as a Foreign Language Classroom in Malta: Practices and perspectives. Unpublished Masters in Teaching and Learning dissertation, University of Malta.

DIACONO, $\dot{\text { G. }}$ (1977) Gheltijiet u Barbariżmi fil-Malti. Valletta: Pubblikazzjonijiet Diacono. DIRECTORATE FOR QUALITY AND STANDARDS IN EDUCATION - CURRICULUM MANAGEMENT AND E-LEARNING DEPARTMENT. (2011) Handbook for the teaching of German as a foreign language. DQSE: Malta.

DIRECTORATE FOR QUALITY AND STANDARDS IN EDUCATION - CURRICULUM MANAGEMENT AND E-LEARNING DEPARTMENT. (2012) French as a foreign language: Teaching Objectives and Learning Outcomes Form 1, Form 2. DQSE: Malta.

DIRECTORATE FOR QUALITY AND STANDARDS IN EDUCATION - CURRICULUM MANAGEMENT AND E-LEARNING DEPARTMENT. (2012) Handbook for the teaching of French as a foreign language. DQSE: Malta.

EDUCATION DIVISION - CENTRE FRANCO-MALTAIS - DEPARTMENT OF CURRICULUM MANAGEMENT. (2001-2002+) Programmes de français. Version $N M C / C M N$. Education Division: Malta.

EHRHART, S. (2002) L'alternance codique dans le cours de langue : le rôle de l'enseignant dans l'interaction avec l'élève - Synthèse à partir d'énoncés recueillis dans les écoles primaires de la Sarre. In LORENZO SUAREZ A.M., RAMALLO F., RODRIGUEZ-YANEZ F.X. (eds.). Proceedings from the Second International Symposium on Bilingualism, University of Vigo, October 2002. Available from:

www.ph-karlsruhe.de/fileadmin/user_upload/dozenten/schlemminger/linguistique/ EHRHART-code-swt-LV.pdf [Accessed 3/9/2016]

FARRELL, M.P. and VENTURA, F. (1998) Words and Understanding in Physics. Language and Education, 12 (4), p. 243-253. 
FARRUGIA, M.T. (2009) Reflections on a Medium of Instruction Policy for Mathematics in Malta. In: BARWELL, R. (ed.) Multilingualism in mathematics classrooms. Bristol: Multilingual Matters, p. 97-112.

FARRUGIA, Y. and MUSCAT, C. (2012) Discourse in secondary physics classrooms. Unpublished dissertation (B. Ed. (Hons.), University of Malta.

GARCIA, O. (2011). Theorizing Translanguaging for Educators. In: CELIC, Ch. and SELTZER, K. Translanguaging: A Cuny-Nysieb Guide for Educators. New York: CunyNysieb,p.1-6.

GAUCI, H. (2011) Teacher codeswitching in the Italian second language classroom in Malta. Unpublished dissertation (M. Ed.), University of Malta.

GAUCI, H. and CAMILLERI GRIMA, A. (2012) Codeswitching as a tool in teaching Italian in Malta. International Journal of Bilingual Education in Malta, DOI:10.1080/13670050.2012.716817

GAUCI, J. (2016). L'alternance codique en classe de FLE dans des collèges maltais: représentations et constatations. Unpublished dissertation (B.Ed. (Hons.), University of Malta. GILES, H. and POWESLAND, P. (1975) A Social Psychological Model of Speech Diversity. In: GILES, H. and POWESLAND, P. (eds.) Speech Style and Social Evaluation. New York: Harcourt Brace, p. 154-170.

GILES, H. and SMITH, P. (1979) Accomodation Theory: Optimal Levels of Convergence. In: GILES, H. and St. CLAIR R.N. (eds.) Language and Social Psychology, Oxford: Blackwell, p.45-65.

GREGGIO, S. and GIL, G. (2007). Teachers' and Learners' use of code switching in the English as a foreign language classroom: Aqualitative Study. Linguagem \& Ensino, 10(2), p. 371-393.

LEE, J. H. and MACARO, E. (2013) Investigating age in the use of L1 or English-Only Instruction: Vocabulary acquisition by Korean EFL Learners. The Modern Language Journal, 97 (4), p. 887-901.

LEVINE, G.S. (2011) Code choice in the language classroom. Bristol: Multilingual Matters.

MAARFIA, N. (2008) L'alternance codique en classe de français en deuxième année primaire: Entre fonction communicative et fonction didactique. Synergies Algérie, 2, p. 93-107.

MACARO, E. (2001) Analysing Student Teachers' Codeswitching in Foreign Language Classrooms: Theories and decision making. The modern language journal 85 (4), p. 531-548.

MOLANDER, L. (2004) L'alternance codique en classe d'immersion: délimitation, interprétation et fonction interactionnelle. Sociolinguistica 18(1), p. 86-105.

MOORE, D. (1996) Bouées transcodiques en situation immersive ou comment interagir avec deux langues quand on apprend une langue étrangère à l'école. AILE 7, p. 95-121.

MOORE, D. (2002) Code-switching and Learning in the Classroom. International journal of bilingual education and bilingualism 5, p. 279-293.

RAMIREZ, A.G. and MILK, R.D. (1986) Notions of Grammaticality among Teachers of Bilingual Pupils. TESOL Quarterly 20, p. 495-513.

SOLLARS, V. (1988) Readability of Science Textbooks in Forms 1 and 2 in Education. The journal of the Faculty of Education, 3 (2), p. 19-26.

SOKU, D. (2014) Alternance codique en classe de FLE : Raisons d'ordre pédagogique chez les enseignants et facteurs de motivation chez les apprenants. Developing Country Studies, 4 (20), p. 1-10.

STOLZ, J. (2011) L'alternance codique dans l'enseignement du FLE. Etude quantitative et qualitative de la production orale d'interlocuteurs suédophones en classe de lycée. Göteborg: Linnaeus University Press.

THOMPSON, G. L. and HARRISON, K. (2014) Language Use in the Foreign Language Classroom. Foreign Language Annals, 47 (2), p. 321-337. 
VENTURA, F. (1991) Language and the Science curriculum in education. The journal of the Faculty of Education 4 (32), p. 8-15.

YIBOE, K. T. (2010) Enseignement/apprentissage du français au Ghana: écartsentre la culture d'enseignement et la culture d'apprentissage.Online Thesis (PhD), University of Strasbourg. Available from:

http://scd-theses.u-strasbg.fr/2419/ [Accessed 24/3/2016] 